\title{
Petrosektomia subtotala kolesteatomaren tratamendurako: 2008- 2018 arteko ikerketa erretrospektiboa duo-n
}

\author{
Subtotal petrosectomy for the treatment of cholesteatoma. Retrospective study \\ in uhd 2008-2018
}

Maitane Alonso Saenz del Burgo

UPV/EHUko Medikuntza eta Erizaintza Fakultateko Donostiako Ikastegia

alonso.maitane@gmail.com

\section{Laburpena}

Kolesteatoma jatorri ezberdineko erdiko belarrian hazten den epitelio ezkatatsu keratinizatuaren bilduma da, tamaina eta kokapenaren arabera klinika zabala eman dezakeena. Kolesteatomaren tratamendua kirurgikoa da, eta tinpanoplastia edota mastoidektomia dira aukerako teknikak. Zenbaitetan, ordea, aukera inbasiboagoetara jo behar da, eta horrelakoetan petrosektomia subtotala (PST) aukera baliagarria bilaka daiteke. Lan honetan Donostia Unibertsitate Ospitalean (DUOn) 20082018 artean erdik obelarriko otitis kronikoaren edota kolesteatomaren tratamendurako egindako petrosektomia subtotalen emaitzak erretrospektiboki aztertu eta literaturan aurkitu diren emaitzekin alderatuko dira. DUOko Otorrinolaringologia Sailean 2008-2018 artean egin ziren PSTen datuak bildu eta indikazioa erdiko otitis kronikoa edota kolesteatoma ziren kasuak aztertu dira, parámetro ezberdinak ikertuz. Bestalde, PubMed datubasean PSTaren inguruko bilaketa bibliografikoa egin da eta DUOko emaitzak PubMed-en aurkitutakoekin alderatu dira. 2008-2018 artean 73 PST egin ziren, indikazio ohikoenak erdiko belarriko otitis kronikoa (\% 31), kolesteatomaren errezidiba (\% 25) eta prozesu tumoralak (\% 29) izanik. PST guztietatik, 35ek izan zuten erdiko otitis kronikoa edota kolesteatoma indikazio gisa. Ospitaleko batez besteko egonaldia 5,74 egunekoa izan zen. Kirurgia ostean batez besteko jarraipen-denbora 3,45 urte izan zen, eta kontrolerako EMNa erabili zen kasuen $\% 48,6 a n$. Maizen agertu ziren konplikazioak honakoak izan ziren: infekzioa, paralisifaziala, hipofuntzio bestibularra, odoljarioa, belarriko fistula eta kolesteatomaren errezidiba. Oro har, DUOko egoera literaturan aurkitutako egoeraren parekoa da indikazioen, kirurgiaaurreko egoeraren, paziente motaren eta egoera audiologikoaren ikuspuntutik. Konplikazioei dagokienez, antzeko portzentajean agertu dira, baina infekzio-tasa handiagoa aurkitu da DUOko seriean, eta, horregatik, ikerketa sakonago bat egin liteke.

Gako-hitzak: Kolesteatoma, erdiko otitis kronikoa, petrosektomia subtotala

\section{Abstract}

Cholesteatoma is a collection of keratinized squamous epithelium of varied origin that grows in the middle ear, capable to produce different clinics depending on its location and size. Its treatment is eminently surgical, being tympanoplasty or mastoidectomy the techniques of choice. Sometimes, however, more invasive techniques such as subtotal petrosectomy (STP) are necessary. This work analyzed the results of the STP performed at the University Hospital of Donostia (UHD) between 2008 and 2018 with the indication of chronic otitis media or cholesteatoma and then compared them with the results found in the literature. The data of the STP carried out between 2008 and 2018 at the UHD otolaryngology service were collected in order to later select those that had chronic otitis media or cholesteatoma as an indication and different parameters were analyzed. In addition, a literature 
search was performed in Pubmed's database on the STP and the results were compared with those of UHD. Between 2008 and 2018, 73 PSTs were performed, being the most frequent indications chronic otitis media (31\%), cholesteatoma recurrence (25\%) and tumour processes (29\%). From all the PST, 35 were indicated in the context of chronic otitis media or cholesteatoma. The average hospital stay was 5.74 days. Average post-surgical follow-up was 3.45 years, using nuclear magnetic resonance (MRI) for control in $48.6 \%$ of cases. The most frequent complications were: infection, facial paralysis, vestibular hypofunction, bleeding, atrial fistula, and recurrence of cholesteatoma. In general, the results of UHD coincide with those found in the literature regarding indications, preoperative situation, type of patient and audiological situation. Regarding complications, they have also appeared in similar proportion, being the infection rate higher in the UHD series, for which we recommend a more directed study.

Keywords: Cholesteatoma, chronic otitis media, subtotal petrosectomy

Bidalia: 2020-02-14

Onartua: 2021-03-29

http://doi.org/10.26876/osagaiz.1.2021.357

\section{Sarrera}

\subsection{Kolesteatoma}

Kolesteatoma terminoak mastoide irtengunean edo erdiko entzukinean kokatzen den epitelio ezkatatsu keratinizatuaren pilaketari egiten dio erreferentzia. Etiologiari dagokionez, kolesteatoma lesio primarioa izan daiteke edo tinpano-mintza zulatzearen zein kirurgiaren ondoriozkoa. Bestalde, jaiotzetiko lesio gisa ere ager liteke. Lehenengoa, oro har, entzumen-tutuaren disfuntzioaren ondorioz agertzen da: erdiko entzukinean presio negatibo mantenduak tinpano-mintzaren erretrakzioa eragiten du medialki, erretrakzio-poltsa sortuz (epitelio ezkatatsu keratinizatuaren hondarrekin) eta aldaketa inflamatorioak eraginez. Bigarrena tinpano-mintza zulatzearen ondorioz (epitelio ezkatatsua zulotik igaro eta erdiko entzukinera iristean) edo iatrogenikoki (kirurgia batean zehar erdiko entzukinean epitelio ezkatatsua inplantatzean) gertatzen da (1).

Kolesteatomak zenbaitetan asintomatikoak izan daitezke, baina hala ez denean, ezaugarri kliniko nabarmenena minik ematen ez duen otorrea da, kronikoa edo denboran zehar askotan errepikatzen dena. Bestalde, zorabioak eta transmisiozko hipoakusia ere ager daitezke. Egoera larrienetan, nerbiosistema zentralean konplikazioak gerta daitezke, hala nola meningitisa, abzesu epidurala edo sigma itxurako zabalguneko tronbosia (2).

\subsection{Kolesteatomaren tratamendua}

Kolesteatomaren tratamendua kirurgikoa da eta bere erauzketan oinarritzen da. Helburuak gaixotasunaren desagerpena, erdiko entzukinaren aireztapena hobetzea, barrunbe lehorra sortzea eta entzumen-mekanismoen berreraikitzea dira (3). Horretarako, tinpanoplastia edota mastoidektomia dira lehen aukerako teknikak, hezur-katearen berreraikitzearekin edo gabe (1). Tinpanoplastia erdiko entzukineko gaixotasunak erradikatu eta hezur-katea berreraikitzen duen teknika da. Mastoidektomia, aldiz, mastoide irtenguneko hezurraren aire-barrunbetxoen irekierari deritzo eta hainbat kasutan egiten da; hala nola a) kolesteatoma erdiko entzukina baino harago zabaltzen denean, b) mastoide-gelatxoak kronikoki infektatzen direnean granulazio-ehunez beteta egoteagatik, c) abzesu subperiostikoa mastoide irtenguneko kortexaren azaleran dagoenean. Zenbaitetan, mastoideko barrunbeak material ezberdinak erabiliz itxi egiten dira (1).

Mastoidektomia-teknika ezberdinak deskribatu dira, eta, orokorrean, bi multzotan sailka daitezke, kanpoko entzukinaren pareta mantentzen bada ("canalwallup") edo suntsitzen ("canalwalldown") bada (1. taula). 
1. taula. Mastoidektomia-teknikak

\begin{tabular}{|c|c|}
\hline “Canal wallup" mastoidektomia & "Canal walldown" mastoidektomia \\
\hline Konbinatua & Mastoidektomia erradikala \\
\hline Mastoidektomia, kanal pareta mantenduz & Mastoidektomia erradikal modifikatua \\
\hline Teknika itxia & Teknika irekia \\
\hline & Aurrez atzerako mastoidektomia \\
\hline & Atikoantrostomia \\
\hline & Epitinpanomastoidektomia irekia \\
\hline
\end{tabular}

Open access atlas ofotolaryngology, headandneckoperativesurgery-tik hartutako taula (3).

Erdiko entzukineko gaixotasun kroniko eta errekurrenteen kasuan, helburua, aipatu bezala, barrunbe osasuntsu eta lehorra lortzea da. Askotan lortzea posible izaten da, gaixotasuna erauziz eta egonkorra den barrunbea eraikiz;baina egoera batzuetan ez da lortzen eta gaixoen bizi-kalitatea asko murrizten da. Halako kasuetan, gaixoak petrosektomia subtotalerako hautagai bilakatzen dira (4).

\subsection{Petrosektomia subtotala (PST)}

Petrosektomia subtotala UgoFischek deskribatu zuen 1965ean "loki-hezurreko aire-barrunbetxo guztien exenterazio" gisa; zehazki aurpegi-nerbioaren kanalaren atzeko, sigma itxurako zabalgunearen atzeko, antroko, labirinto atzeko, labirinto gaineko, labirinto azpiko, entzumen-tutu inguruko eta karotida-kanal inguruko barrunbeen erauzketa. Hezurrezko labirintoa kontserbatu egiten zen, hasiera batean behintzat (kirurgia zabaltzeko aukera zegoen koklea, labirintoa edo barneko entzukina erauziz, behar izanez gero), eta kanpoko entzukinaren itxiera posiblea zen, baina ez beharrezkoa (5).

Gaur egun, "petrosektomia subtotala" terminoa nahiko anbiguoa da eta askotan zentzu hertsian petrosektomiak ez diren kasuetan erabiltzen da. Horrek nahasketak dakartza indikazioak zehazteko garaian (4).

PSTa honela definitzen da: "loki-hezurraren aire-barrunbetxo guztien erauzketa" (sigma itxurako zabalgunearen atzeko, aurpegi-nerbioaren kanal atzeko, antroko, labirinto atzeko, tutu gaineko eta karotida-kanal ingurukoak). Hezurrezko labirintoaren erauzketa hautazkoa da, kanpoko entzukina zaku itxi baten moduan ixten da eta barrunbe kirurgikoa abdomeneko gantzarekin bete eta zintzilikario batekin isolatzen da (6).

PSTa hainbat patologiatan izan daiteke baliagarria; haren indikazioak 2.taulan laburtzen dira.

2. taula: PSTaren indikazioak.

\section{PSTaren indikazioak}

\begin{tabular}{|c|}
\hline PSTaren indikazioak \\
\hline Erdiko belarriko otitis kronikoa \\
\hline Erdiko belarriko tumoreak \\
\hline LZR fistula traumatiko, iatrogeniko edo berezkoak \\
\hline Labirinto gaineko edota azpiko kolesteatoma \\
\hline Loki-hezurraren zeharkako hausturak \\
\hline Beste prozesu neuro-otologikoekin elkarketan (garezurraren alboko abordatzearen \\
aurretik) \\
\hline Hezur tenporalaren osteorradionekrosia \\
\hline Inplante auditiboak \\
\hline
\end{tabular}




\subsubsection{Prozedura}

PSTaburutu aurretik, pazienteek ordenagailu bidezko tomografia axiala (OTA) eta audiograma egin eta zain bidezko antibiotikoa jaso behar dute (amoxizilina etaazido klabulanikoa). Prozeduran zehar, pazientea buruz gora etzaten da, burua kirurgialariaren kontrako aldeari begira. Bestalde, aurpeginerbioaren monitorizazioa egiteko, anestesian erlaxazio muskularra ekidin behar da ahal den neurrian (6).

Prozedura kirurgikoari dagokionez, lau urratsetan banatu daiteke:

1. Azalaren ebakidura eta kanpoko entzukina altxatzea: a) Belarri atzeko abordatzea erabiliz azala "S" formarekin ebakitzen da (1. irudia-A). b) Zintzilikario periostiko errektangularra sortzen da mastoide irtengunearen kortexetik, geroago kanpoko entzumen-kanalaren itxieran bigarren geruzagisa erabiltzeko. Beraz, zintzilikarioak kanpoko entzumen-kanala estaltzeko luzera nahikoa izan behar du (1. irudia-B).

2. Kanpoko entzumen-kanalaren itxiera: d) Kanpoko entzumen-kanala atzeko paretatik irekitzen da ebakidura baten bidez, kanalaren kartilagozko eta hezurrezko zatiek elkarrekin bat egiten duten gunean. Ondoren, kanalaren aurreko pareta ere irekitzen da (1. irudia-D).e) Barrunbe kirurgikoa etorkizunean ireki ez dadin, funtsezkoa da kanpoko entzumen-kanalaren kartilagozko atala zaku itxi moduan oso ondo ixtea. Horretarako, kanalaren kartilagozko atala ebakitako gunetik gutxienez $1 \mathrm{~cm}$ altxatu behar da (1. irudia-E).f) Behin azala askaturik, ertzak behin-behineko 2-0 vicryl hariz josi behar dira, eta hariaren mutur askeak kanalaren barnealdean uzten dira (1. irudia-F).g) Kanalaren kanpoaldetik clamp bat sartzen da, barnealdean gelditu diren harien mutur askeak hartu eta, tira eginez, azala barrukoz kanpora tolesteko. Ostean, azalaren ertzak berriro ere josten dira, 4-0 vicryl hariz, zaku itxia ongi finkatzeko (1. irudia-G).h) Hasieran sortutako zintzilikario periostikoarekin kanpoko entzumen-kanalaren zaku itxia alde medialetik estaltzen da bigarren babes-geruza gisa, inguruko ehun bigunei 2-0 vicryl hariz josiz (1. irudia-H).i) Kanpoko entzukinaren hezurrezko zatiaren alboaldeko muturrean dagoen soberako larruazala harraskagailu batekin altxatu eta tinpanoplastiarako guraizeekin moztu egiten da. j) Kanpoko entzukinaren hezurrezko zati medialenean dagoen azala, tinpanoaren anuluseraino, erauzi egiten da.k) Erdiko entzukinera atzeko zutabe tinpanikotik sartueta anulusa altxatu egiten da. Orduan, tinpano-soka moztu egiten da Bellucci guraizeekin, ingude-estribuetako artikulazioa banatu egiten da 1,5 mm eta 45--ko gako batekin, mailua bere idunetik mozten da eta tinpanoaren gihar tinkatzailearen tendoia moztu egiten da Bellucci guraizeekin. Azkenik, tinpano-mintza erauzi egiten da (mailuaren adarra lotuta duela) eta mailuaren burua eta ingudea ere kentzen dira (2. irudia-I).

3. Aire-barrunbetxoen eta bide guztien exenterazioa: I) Harraskagailumastoideoa erabiliz, mastoide irtengunearen kortexaren gaineko ehun bigun guztiak altxatzen dira eta esternokleidomastoide giharra mastoide irtengunearen puntan duen lotunetik askatu egiten da (2. irudia-J). m) Lokihezurraren disekzioa kanpoko entzumen-kanalaren hezurrezko zatiaren eta epitinpano eta mastoide inguruko hezur kortikalaren erauzketarekin hasten da, barrunbe erradikal bat sortzeko. Hiru egitura eskeletonizatu egiten dira: sigma itxurako zain-zabalgunea, zabalgunearen eta dura-materraren angelutik jugular-erraboilera; aurpegi-nerbioa, belaun-gongoiletik estiloide-mastoideetako foramenera; eta zirkulu erdi-itxurako kanalak (2. irudia-K).n) Mastoide-gelatxo guztiak ongi garbitu eta fresatu behar dira, mukosa guztia kenduz, mastoidektomia ireki baten moduan, hurrengo ordenari jarraituz: sigmoide zabalgune atzeko barrunbea, aurpegi-kanal atzekoa, labirinto atzekoa, labirinto gainekoa, tutu gainekoa, labirinto azpikoa eta karotida-kanal ingurukoa (2. irudia-L). o) Mastoide irtengunearen puntako hezurra, digastriko giharraren alboko aldea estaltzen duena, rongueur batekin kentzen da, estiloide-mastoideetako foramena identifikatzean sortu den hausturalerroari jarraituz.

4. Entzumen-tutuaren eta barrunbe kirurgikoaren obliterazioa: p) Entzumen-tutuko mukosa kendu eta hezur-argizaria sartzen daistmoraino. Ondoren, loki-giharraren injerto batekin erabat ixten da tutua (3. irudia-M). q) Sortutako barrunbe kirurgikoa abdomeneko beheko ezkerreko kouadrantetik lortutako gantzarekin betetzen da (3. irudia-N). r) Belarri atzeko ebakiazabaldu egiten da loki-giharra 
hobeto antzemateko. Ondoren, gihar horren atzealdeko bi herenak askatu egiten dira lokihezurraren ezkatatik beherantz errotatuz zintzilikario gisa mastoide irtenguneko barrunbearen gain kokatzeko. Zintzilikarioa ongi finkatzeko, esternokleidomastoide giharrari josten zaio 2-0 vicryl hariz (3. irudia-O). s) $3 \mathrm{~mm}$-ko xurgatze-drainatze bat uzten da loki-hezurraren atal ezkatatsuan, azalaren azpian. t) Zauri kirurgikoa geruzaz geruza ixten da, azal azpiko planoa 2-0 vicryl hariz josiz eta azala grapaz itxiz. Ondoren bendaje konpresiboa aplikatzen da $(6,7)$.

Prozedura kirurgikoaren ostean, pazienteek tratamendu antibiotikoa (amoxizilina etaazido klabulanikoa) astebetez jasotzen dute. Drainatzearen debitoa $10 \mathrm{ml} / 24 \mathrm{~h}$ baino gutxiago denean kentzen da, PSTaren indikazioa likido zefalorrakideoaren (LZR) jarioa izan denean izan ezik; azken kasu horretan operazio osteko lehen egunean kentzen da drainatzea. Azaleko grapak 10 egun ostean eta jostura-materiala 4 asteren ostean kentzen dira. Jarraipena egiteko OTA edo erresonantzia magnetiko nuklearra (EMN) egingo zaie, kirurgia bultzatu duen arrazoiaren eta beste baldintzatzaileen arabera (6).

1. Irudia: Teknika kirurgikoa (I). Ugo Fisch eta Douglas Mattoxek 1988an argitaratutako Microsurgery of theskull base-tik lortutako irudiak (7). a) Belarriatzeko S motako ebakia. b) Zintzilikario periostikoaren sorrera. d) Kanpokoentzumen-kanalarenirekiera. e) Kanpoko entzumen-kanalaren azalararen askatzea. f) Kanpoko entzuki-netik askatutako azalaren ertzen jostura hastea. g) Azalaren barrukoz kanporako tolestura belarritik kanporantz eta josturaren amaitzea. h) Kanpoko entzumen-analaren alde medi-ala zintzilikario periostikoarekin estaltzea.

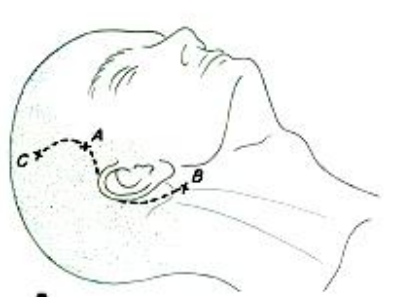

A

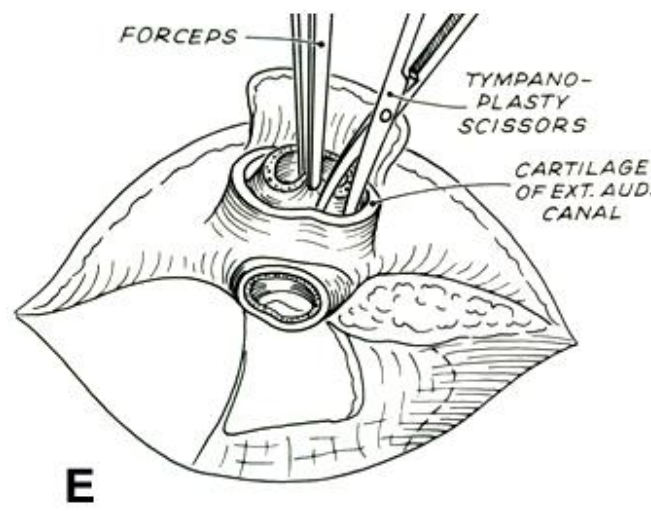

B
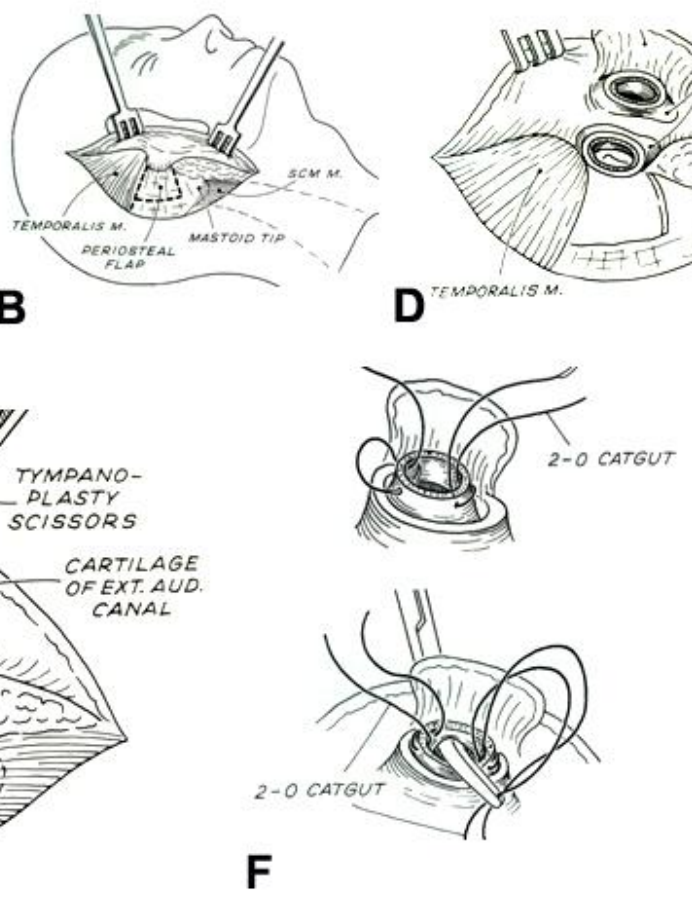
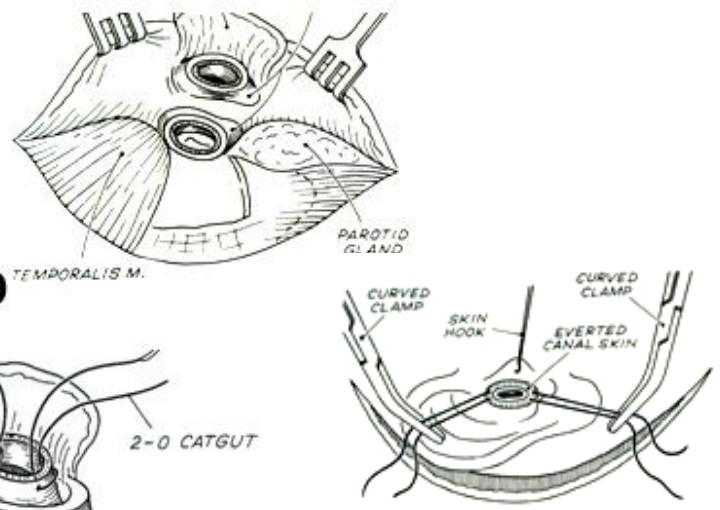

G

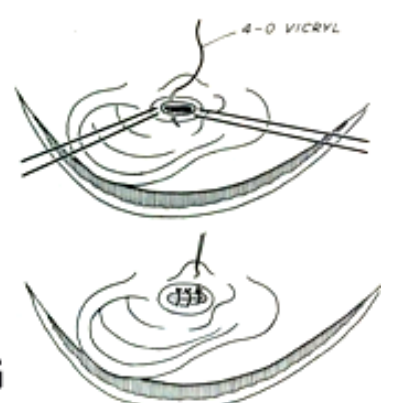

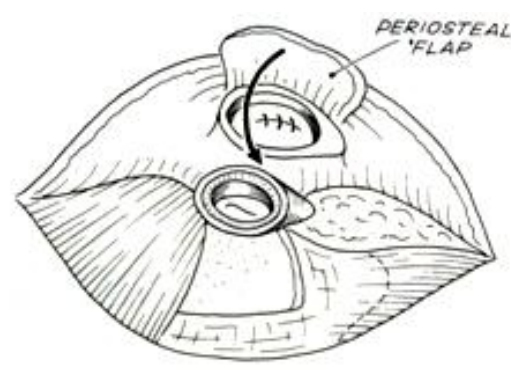

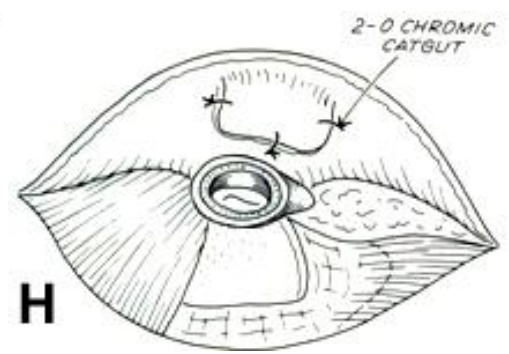


2. irudia. Teknika kirurgikoa (II): Ugo Fisch eta Douglas Mattox-ek 1988an argitaratutako Microsurgeryoftheskull base-tik lortutako irudiak (7). I) Kanpoko entzukinaren hezurrezko zatiko azalaren erauzketa, atzeko zutabe tinpanikotik erdiko entzukinera sartu eta tinpano-soka, igudeestribuetako artikulazioa, mailua eta tinpanoaren gihar tinkatzailea banatzea eta tinpanomintzaren erauzketa. J) Mastoide irtengune inguruko ehun bigun guztien altxatzea. K) Barrunbe erradikalaren sorrera: kanpoko hezurrezko entzumen-kanal, epitinpano eta mastoide inguruko hezur kortikalaren erauzketa eta sigma itxurako zabalgunearen, aurpegi-nerbioaren eta zirkulu erdi-itxurako kanalen eskeletonizazioa. L) Mastoide-gelatxoen garbitze eta fresatzea: sigmoide atzekoa, aurpegi atzekoa, labirinto atzekoa, labirinto gainekoa, supratubarikoa, infralabirintikoa eta perikarotideoa.
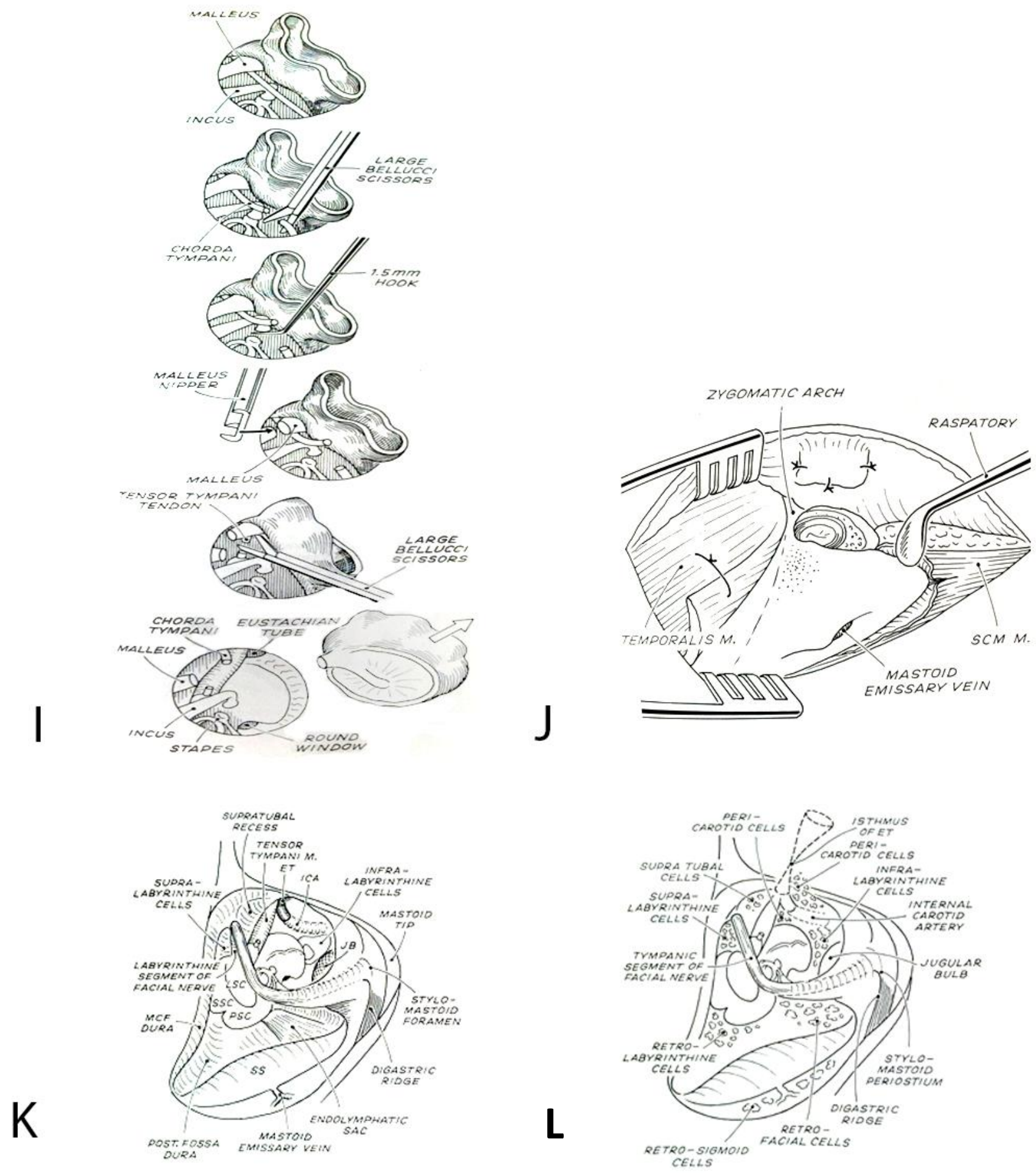


\subsubsection{Entzumen-errehabilitazioa}

PSTa egitean, transmisiozko hipoakusia nabarmena eragiten da (50-60 dB arte) (8). Horregatik, PSTa egin ostean entzumenaren errehabilitazioa egiteko zenbait aukera daude, pazientearen egoera preeta postkirurgikoan oinarrituta. Erabakia hartzeko irizpide garrantzitsuenetakoa pazientearen erreserba koklearra da.

Alde batetik, "boneconductingimplant" (BCl) sistema erabil daiteke. Horien artean, BoneAnchoredHearingAid (BAHA) da ezagunena. $\mathrm{BCl}$ sistemek hezurraren bidez hedatzen dituzte soinu-uhinak; mekanismo hori dela eta, kanpoko eta erdiko entzukinen egoerak ez die eragiten, eta barruko entzukinaren erreserba egokia dagoen kasuetan erabil daitezke (9).

Azken urteetan "middleearimplant" sistema ere garatu da. Aurrekoaren mekanismo ezberdinen bidez jokatzen du, zuzenean leiho obalaren mintza estimulatuz, baina kasu honetan ere barruko entzukineko erreserbak egokia izan behar du inplantatu ahal izateko (10).

Bestalde, barruko entzukineko erreserba nahikoa ez denean, zuzenean nerbioa estimulatuko duen inplante koklearra jar liteke.

3. irudia. Teknika kirurgikoa (III): UgoFisch eta Douglas Mattox-ek 1988an argitaratutako Microsurgeryoftheskull base-tik lortutako irudiak (7). M) Mastoide irtengunearen puntaren erauzketa. N) Entzumen-tutua hezur-argizariz betetzea. 0 ) Mastoide-barrunbea abdomeneko gantzarekin bete eta zintzilikario bidezko itxiera.
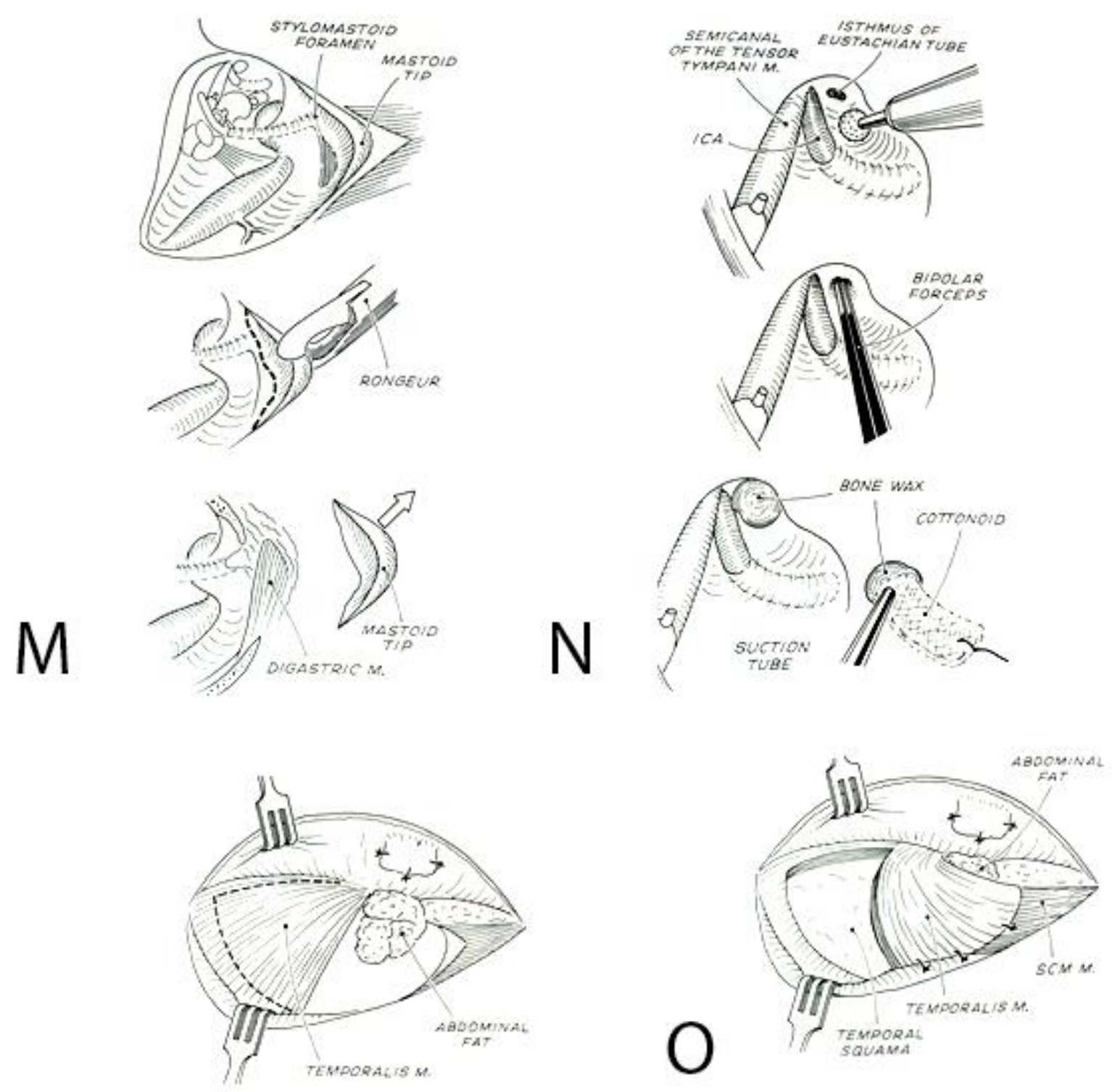


\section{Helburuak}

Lan honetan DUOn 2008-2018 artean erdiko otitis kroniko edota kolesteatomaren tratamendurako egindako petrosektomia subtotalen emaitzak erretrospektiboki aztertu eta literaturan aurkitu diren emaitzekin alderatuko dira.

\section{Material eta metodoak}

Lan honen sarrera osatu eta gaiari buruzko informazio orokorra biltzeko UpToDate eta eMedicine orrialdeetan "cholesteatoma" bilaketa egin eta horren inguruko artikulu bana jaso da. PubMed datubasea ere erabili da hurrengo gako-hitzak erabiliz: "cholesteatoma", "cholesteatomadefinition", "subtotal petrosectomy", "cholesteatomasurgery", "subtotal petrosectomy AND cholesteatoma", "mastoidectomy" eta "subtotal petrosectomy technique". Laburpenak irakurriz, gaiarekin zerikusia zuten artikuluak hautatu dira. Bestalde, Lurmutur Hiriko Unibertsitateak (CapeTownUniversity) eskuragarri duen otorrinolaringologia, buruko eta iduneko kirurgiaren atlas irekian mastoidektomia eta petrosektomia subtotalaren prozedurari buruzko artikuluak lortu dira.

Donostiako Unibertsitate Ospitalean (DUO) 2008-2018 artean egindako PSTen datuak lortzeko, zerbitzuak duen fitxategian PSTa jasan zuten pazienteen historia klinikoaren zenbakia eskuratu da, guztira 73 lortuz. Ondoren, paziente bakoitzaren datuak lortzeko Osabide Global programa erabili da. Historia klinikoen bidez pazienteen fitxategian aldez aurretik zehaztutako parametroen bilaketa egin da. Aztertu diren parametroak honakoak izan dira: sexua, adina, komorbilitateak, aurreko kirurgia otorrinolaringologikoak, indikazio kirurgikoa, interbentzio mota, lateralitatea, ospitale-egonaldia, jarraipenerako teknika eta iraupena, konplikazioak, kirurgia aurreko eta ondorengo audiometriak eta inplanteen erabilera. 73 pazienteetatik 15 baztertu dira ez zutelako PSTrik jasan, eta 58 pazienteren datuak bildu dira (1. Eranskinaeta2. eranskina). PST guztien artean, indikazioa kolesteatoma edota erdiko belarriko otitis kronikoa zuten kasuak aukeratu dira emaitzak ateratzeko, guztira 35 paziente izanik.

\section{4. irudia. Aztergai diren kasuen aukeraketaren diagrama}

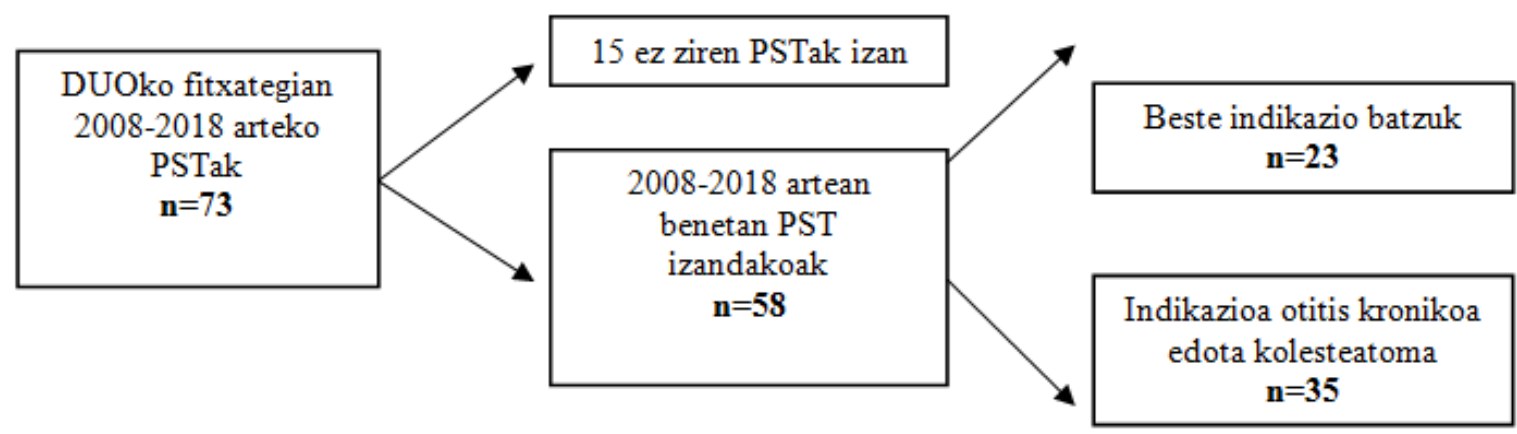

Lan hau egin aurretik, DUOko otorrinolaringologia (ORL) zerbitzuak dagoeneko Etika Batzordearen baimena zuen pazienteen historia klinikoan aipatutako datuak aztertzeko. Baimen hori lan hau egin bitartean oraindik indarrean zegoenez, ez da beharrezkoa izan berriro ere eskatzea.

PSTaren emaitzak literaturan zein izan diren balioztatzeko, PubMed datu-basea erabili da honako terminoak bilatuz: "subtotal petrosectomy", "mastoidectomy with blinds acclosure ofext ernal auditory canal" eta "mastoidectomy with total obliteration". Guztira 160 artikulu aurkitu dira, eta horietatik 18k zeukaten lotura aztertu nahi zen gaiarekin. Bat baztertu da (Altuna, 2016) DUOn eginda zegoelako, ikerketa honetan erabiliko diren datuekin bikoizketak saihesteko. Aurkitutako artikulu bakoitzetik hainbat datu bilduz taula bat osatu da (3. eranskina). Jaso diren datuak hauek izan dira: paziente kopurua, adina, sexua, aurreko kirurgiak, indikazio kirurgikoa, lateralitatea, jarraipena, jarraipenerako teknika, konplikazioak, kirurgia aurreko entzumena zein zen eta inplanteen erabilera. Taulan bildutako serieen datuak DUOko emaitzekin alderatu dira. 


\section{Emaitzak}

\subsection{8-2018 arteko PST guztien emaitzak}

2008-2018 artean Donostiako Unibertsitate Ospitalean 58 PST egin ziren. Batez besteko adina 56,45 urte $(6-89$ tartea) izan zen eta 39 gizon $(\% 67,24)$ eta 19 emakume $(\% 32,76)$ operatu ziren. Paziente horien datu demografikoak 3.taulan bilduta daude.

Egin ziren PST guztiak kontuan hartuta, indikazio kirurgiko ohikoenak erdiko belarriko otitis kronikoa (\% 31), kolesteatomarenerrezidiba $(\% 25)$ eta prozesu tumoralak (\% 29) izan ziren. 4. taulan laburbiltzen dira kasu guztien indikazioak eta maiztasuna.

3. taula:2008-2018 artean DUOnPSTa jasotako paziente guztien datu demografikoak

\begin{tabular}{|c|c|}
\hline Paziente kopurua & 58 \\
\hline Gizonak & $39(\% 67,24)$ \\
\hline Emakumeak & $19(\% 32,76)$ \\
\hline Batez besteko adina & 56,45 urte \\
\hline Adin- tartea & $6-89$ urte \\
\hline \multicolumn{2}{|l|}{ Komorbilitateak } \\
\hline$\leq 2$ & $23(\% 39,65)$ \\
\hline $3-5$ & $25(\% 43,1)$ \\
\hline$\geq 6$ & $10(\% 17,24)$ \\
\hline \multicolumn{2}{|l|}{ Aldea } \\
\hline Eskuin & $28(\% 48,28)$ \\
\hline Ezker & $30(\% 51,72)$ \\
\hline Ospitaleko batez besteko egonaldia & 7 egun \\
\hline
\end{tabular}

4. taula:2008-2018 artean DUOn egindako PST guztien indikazioak

\begin{tabular}{|c|c|c|}
\hline Indikazio kirurgikoa & Kopurua & $\%$ \\
\hline $\begin{array}{l}\text { Erdiko belarriko otitis kronikoa } \\
\text { (kolesteatomarekin edo gabe) }\end{array}$ & 18 & 31,03 \\
\hline Kolesteatomarenerrezidiba & 15 & 25,86 \\
\hline Kolesteatomaz bestelako prozesu tumoralak & 17 & 29,31 \\
\hline Inplante auditiboak & 3 & 5,17 \\
\hline Labirinto gaineko eta ezpiko kolesteatomak & 2 & 3,44 \\
\hline Loki-hezurraren zeharkako hausturak & 1 & 1,72 \\
\hline Loki-hezurraren osteoerradionekrosia & 1 & 1,72 \\
\hline Kanpo entzukinaren estenosi post-traumatikoa & 1 & 1,72 \\
\hline Guztira & 58 & 100 \\
\hline
\end{tabular}

\subsection{8-2018 artean erdiko otitis kroniko edota kolesteatoma indikazioa zuten petrosektomia subtotalen emaitzak}

PST kasu guztiak gainetik aztertu ondoren, indikazioa erdiko otitis kronikoa edota kolesteatoma duten kasuetan zentratu eta zehatzago aztertu dira. DUOn 2008-2018 artean egin ziren 58 PSTetatik, $35 \mathrm{ek}$ izan zuten aipatutako indikazio hori $(\%$ 60,34). Paziente talde horren ezaugarri demografikoak 5.taulan laburbiltzen dira. Aldez aurreko interbentzio kirurgikoak aztertuz, 24 pazientek $(\% 68,57)$ PSTa egin aurretik entzumen-organoan interbentzioren bat izan zuten eta soilik 11 pazienteren kasuan $(\% 31,43)$ izan zen PSTa aurreneko kirurgia. 
5. taula: 2008-2018 artean DUOn erdiko otitis kronikoagatik edota kolesteatomagatikPSTa jaso zuten pazienteen datu demografikoak.

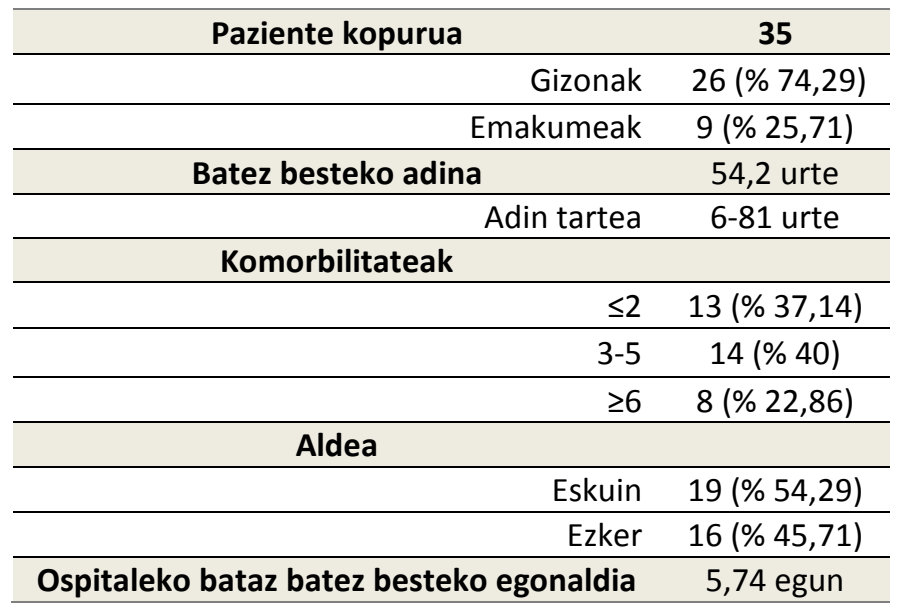

Kirurgia ostean paziente guztiek izan zuten jarraipena DUOkoORL zerbitzuan denbora ezberdinean zehar. Batez besteko jarraipen-denbora 3,45 urte izan zen, gutxieneko jarraipena sei hilabetekoa izanik, eta gehienekoa hamar urtekoa (mediana: 5,25 urte). Jarraipena egiteko historia kliniko eta esplorazio egokiaz gain, gehienetan proba osagarriak eskatu ziren, ohikoena EMNa izanik $(\% 48,6)$. Erabili ziren probak 6. taulan deskribatzen dira maiztasunaren arabera antolatuak.

6. taula: DUOn kirurgia osteko jarraipena egiteko erabili diren proba osagarriak, maiztasunaren arabera sailkatuak.

\begin{tabular}{rcc}
\hline Jarraipen-teknika & Zenbakia & $\mathbf{\%}$ \\
\hline EMN & 17 & 48,57 \\
\hline Audiometria & 11 & 31,43 \\
\hline OTA & 3 & 8,57 \\
\hline EMN eta OTA & 3 & 8,57 \\
\hline Gabe & 1 & 2,86 \\
\hline
\end{tabular}

\subsubsection{Konplikazioak}

Operazio osteko garaian hainbat konplikazio kontabilizatu ziren. Bi taldetan banatuz, alde batetik goiztiarrak eta beste alde batetik berantiarrak, guztira 32 izan ziren (7. taulan deskribatzen dira).

Konplikazio goiztiarren artean lau infekzio zenbatu ziren, horietatik bat fistulizatutako abzesua izanik. Laurek behar izan zuten zain bidezko antibiotikoa eta tratamendu kirurgikoa ebazpena lortzeko. Gune kirurgikoaren infekzio soilaren hiru kasuetan eragileak Pseudomonasaeruginosa eta bakterio gram negatiboak izan ziren eta barrunbearen garbiketa kirurgikoa behar izan zuten, loki-eskualdeko zintzilikarioa gehituz aurreko prozedurari. Fistulizatutako abzesuaren kasuan $S$. epidermidis multirresistentea izan zen eragilea, eta drainatze kirurgikoa eta fistularen itxiera egin behar izan zen. Ostera, azken paziente horri, antibiotikoekin ongi sendatu zen abzesu parenkimatoso antolatu bat sortu zitzaion.

$\mathrm{Bi}$ aurpegi-paralisi zenbatu ziren lehen momentuetan: lehenengoa, tratamendurik gabe berez sendatu zen bekoki-aldeko adarraren paresia arina izan zen 62 urteko gizon batengan. Bigarrengoa, 15 urteko gizon batengan, House-Brackmann eskalako VI graduko paralisia izan zen eta errehabilitazioarekin IV. gradukoa izatea lortu zen. Hiru kasuetan agertu zen hipofuntzio bestibularra (ezegonkortasuna, bertigo periferiko paroxistiko onbera, akufenoak) eta kasu guztiak sendatzea lortu zen tratamendu farmakologiko eta bertigo-unitateko errehabilitazioaren bidez.

Gainerako konplikazio goiztiarrak (edema palpebrala, flebitisa, laringoespasmoa eta fibrilazio aurikular sintomatikoa) taulan deskribatuta daude, laurak izan ziren konplikazio arinak eta tratamendu ez-kirurgikoaren bidez sendatzea lortu zen. 
Konplikazio berantiarren artean, bost infekzio-kasu agertu ziren. Horietatik lau antibiotikoa behar izan zuten azaleko infekzioak izan ziren, arazo gabe sendatu zirenak. Azkeneko infekzioa abzesu bat izan zen, PSTaren ondoren bi urte igaro ostean agertutakoa, inplante auditiboa ezartzeko bigarren interbentzioaren ondoren, eta PSTarenerrebisio kirurgikoa behar izan zuen. Gerora hematoma agertu eta drainatzea ere behar izan zuen erabat sendatzeko.

Bi pazienteri belarriko fistula sortu zitzaien PSTaren osteko lehen urteko epean: lehena komorbilitate gutxi zuen 25 urteko emakume bat izan zen eta bi aldiz operatu behar izan zen sendatzeko (fistularen itxiera, barrunbearen errebisio eta garbiketa kirurgikoa eta zintzilikarioaren ezarpena). Bigarrengo fistularen kasua 60 urteko gizon bat izan zen; kasu horretan, kirurgikoki fistula ixtea eta esternokleidomastoide-zintzilikarioa ezartzea erabaki zen. Gerora zorne-jario arina izan zuen belarri atzeko zulotik, baina tratamendu medikoarekin eboluzio ona izan zuen.

Hiru kasuetan aurkitu zen kolesteatomarenerrezidiba, PSTtik lau, bost eta sei urte igaro ostean. Errezidiba irudi-proben bidez aurkitu zen bi kasutan eta zorne-jario kronikoaren klinikagatik bestean. EMN bidezko urteroko jarraipena egitea erabaki zen bi pazienteetan, eta hirugarrengoari mastoidektomiaren errebisioa egin zitzaion.

Gainontzeko konplikazio berantiar arinak (otorrea, seroma, orbaina, mareoa eta artikulazio tenporomandibularraren disfuntzioa) taulan deskribatuta daude, eta berez edo tratamendu medikuaren laguntzaz konpondu ziren.

7. taula. PSTaren osteko konplikazio goiztiar eta berantiarrak, eta haien maneiua eta ebazpena

\begin{tabular}{|c|c|c|c|c|}
\hline Konplikazioak & Kopurua & $\%$ & Maneiua & Emaitza \\
\hline Goiztiarrak & 16 & 45,71 & & \\
\hline Infekzioa & 4 & 11,43 & $\begin{array}{l}\text { Zain barneko ATB/ } \\
\text { prozedura kirurgikoa }\end{array}$ & $\begin{array}{c}2 \text { kasuetan sendaketa } \\
\text { zuzenean. Bestean ATB } \\
\text { mantendu behar izan } \\
\text { zen sendaketa lortu } \\
\text { arte }\end{array}$ \\
\hline Aurpegi-paralisia & 2 & 5,71 & $\mathrm{RHB}$ & Hobekuntza/sendaketa \\
\hline Hipofuntzio bestibularra & 3 & 8,57 & $\begin{array}{c}\text { Tratamendu } \\
\text { farmakologikoa eta bertigo } \\
\text { unitateko RHB }\end{array}$ & Hobekuntza \\
\hline $\begin{array}{r}\text { Odoljarioa/ belarri atzeko } \\
\text { hematoma }\end{array}$ & 3 & 8,57 & Konpresioa & Sendaketa \\
\hline Betazaleko edema & 1 & 2,86 & Tratamendu medikoa & Sendaketa \\
\hline Flebitisa & 1 & 2,86 & Kateterra kendu & Sendaketa \\
\hline Laringoespasmoa & 1 & 2,86 & $\begin{array}{c}\text { Anestesistaren } \\
\text { tratamendua }\end{array}$ & Sendaketa \\
\hline FA sintomatikoa & 1 & 2,86 & Errebertsioa & Kontrolatua \\
\hline Berantiarrak & 15 & 42,86 & & \\
\hline Infekzioa & 5 & 14,29 & ATB/prozedura kirurgikoa & Sendaketa \\
\hline Belarri-fistula & 2 & 5,71 & $\begin{array}{c}\text { Prozedura kirurgikoa } \\
\text { (fistularen itxiera eta } \\
\text { zintzilikarioa ezarri) }\end{array}$ & $\begin{array}{l}\text { Sendaketa/supurazio } \\
\text { arina mantendu }\end{array}$ \\
\hline Kolesteatomarenerrezidiba & 3 & 8,57 & $\begin{array}{c}\text { Irudi-proba bidezko } \\
\text { jarraipena/mastoidektomia }\end{array}$ & Kontrola/sendaketa \\
\hline Aldizkako otorrea & 1 & 2,86 & Kontrol medikoa & Berezko etetea \\
\hline Seroma & 1 & 2,86 & Konpresioa & Sendaketa \\
\hline Orbain hipertrofikoa & 1 & 2,86 & Dermatologiara deribatua & Ezezaguna \\
\hline ATMaren disfuntzioa & 1 & 2,86 & AIEE & Sendaketa \\
\hline Zorabioa eta akufenoak & 1 & 2,86 & Tratamendu gabe & Berezko hobekuntza \\
\hline Guztira & 32 & & & \\
\hline
\end{tabular}




\subsubsection{Emaitza audiologikoak}

Egoera audiologikoari dagokionez, 9 pazientek kofosia zuten interbentzio aurretik (\% 25). Gainontzekoen artean hipoakusia mistoa, transmisiozko hipoakusia eta hipoakusia neurosentsoriala \% 23an, \% 20an eta \% 17an aurkitu ziren, hurrenez hurren. PSTa egin ondoren pazienteen egoera audiologikoa okertu egin zen $\% 34,29$ an (8. taula).

8. taula. Pazienteen kirurgia osteko egoera audiologikoa, kirurgia aurreko egoera audiologikoaren arabera banatuta.

\begin{tabular}{|c|c|c|c|c|c|c|}
\hline \multirow{2}{*}{$\begin{array}{c}\text { Kirurgia aurreko } \\
\text { egoera } \\
\text { audiologikoa }\end{array}$} & \multicolumn{4}{|c|}{ Kirurgia osteko egoera audiologikoa } & \multirow[b]{2}{*}{ Guztira } & \multirow[b]{2}{*}{$\%$} \\
\hline & Mantendu & Okertu & $\begin{array}{c}\text { Hobetu } \\
\text { (inplantea) }\end{array}$ & $\begin{array}{l}\text { Zehaztu } \\
\text { gabe }\end{array}$ & & \\
\hline Kofosia & 9 & 0 & - & - & 9 & 25,71 \\
\hline Hipoakusiamixtoa & 1 & 3 & 2 & 2 & 8 & 22,86 \\
\hline $\begin{array}{r}\text { Transmisiozko } \\
\text { hipoakusia } \\
\end{array}$ & 2 & 4 & 1 & - & 7 & 20 \\
\hline $\begin{array}{r}\text { Hipoakusia } \\
\text { neurosentsoriala }\end{array}$ & - & 3 & 2 & 1 & 6 & 17,14 \\
\hline $\begin{array}{r}\text { Zehaztu gabeko } \\
\text { hipoakusia }\end{array}$ & - & 2 & - & 1 & 3 & 8,57 \\
\hline Normala & - & - & 1 & - & 1 & 2,86 \\
\hline Ezezaguna & - & - & - & 1 & 1 & 2,86 \\
\hline Guztira & $\begin{array}{c}12 \\
(\% 34,29)\end{array}$ & $\begin{array}{c}12 \\
(\% 34,29)\end{array}$ & $\begin{array}{c}6 \\
(\% 17,14)\end{array}$ & $\begin{array}{c}\mathbf{5} \\
(\% 14,28)\end{array}$ & $\begin{array}{c}35 \\
(\% 100)\end{array}$ & 100 \\
\hline
\end{tabular}

Entzumen-errehabilitazioaren ikuspegitik, 16 pazientek jaso zuten inplantea entzumena hobetzeko asmoarekin: zortzik PST interbentzio berean eta zortzik bigarren denbora batean. Gailu ezberdinak erabili ziren horretarako: alde batetik, hamar pazienterentzat inplante osteointegratuak (Ponto edo Superpower, besteak beste) erabili ziren; bestetik, bost pazientek inplante koklearra jaso zuten eta, azkenik, paziente bati erdiko entzukineko inplante aktiboa ezarri zitzaion.

9. taula: Inplanteen erabilera pazientearen kirurgia aurreko egoera auditiboaren arabera banatuta.

\begin{tabular}{rcccc}
\hline $\begin{array}{c}\text { Kirurgia aurreko } \\
\text { egoera audiologikoa }\end{array}$ & Kopurua & $\begin{array}{c}\text { Inplanteen } \\
\text { erabilera }\end{array}$ & $\begin{array}{c}\text { PST kirurgian } \\
\text { bertan ezarritako } \\
\text { inplante kopurua }\end{array}$ & $\begin{array}{c}\text { PST kirurgian bertan } \\
\text { ezarritako inplante } \\
\text { mota }\end{array}$ \\
\hline Kofosia & 9 & 1 & 0 & 2 IK \\
\hline $\begin{array}{r}\text { Hipoakusia mistoa } \\
\text { Transmisiozko } \\
\text { hipoakusia }\end{array}$ & 7 & 3 & 1 & IOI \\
\hline $\begin{array}{r}\text { Hipoakusia } \\
\text { neurosentsoriala }\end{array}$ & 6 & 5 & 3 & $1 \mathrm{EBIA}, 2$ IK \\
\hline $\begin{array}{r}\text { Zehaztugabeko } \\
\text { hipoakusia }\end{array}$ & 3 & 2 & 1 & 1 IOI \\
\hline Normala & 1 & 1 & 1 & 1 IK \\
\hline Ezezaguna & 1 & 0 & 0 & - \\
\hline Guztira & $\mathbf{3 5}$ & $\mathbf{1 6}$ & $\mathbf{8}$ &
\end{tabular}

$E B \mid A=$ erdiko entzukineko inplante aktiboa; $I O I=$ inplante osteointegratua; $I K=$ inplante koklearra.

\section{Eztabaida}

Literaturan aztertu diren PST serieetako indikazioak DUOkoen antzekoak izan dira; kirurgia honetara jotzeko arrazoi ohikoenetarikoa erdiko belarriko otitis kronikoa izanik $(9,11,12,13)$. 
Erdiko belarriko otitis kronikoak edota gaixotasun kolesteatomatosoek zenbait egoeratan ez diete lehen lerroko aukera terapeutikoei ongi erantzuten eta pazientearen egunerokotasuna asko mugatzen dute, bai zorne-jario kronikoa sortzen dutelako baita aurrera egin eta hainbat konplikazio ager daitezkeelako ere. Hori dela eta, askotan, PSTa egoera jasanezin baten azken urratsa da, kasu zehatz batzuetan lehen aukera terapeutikoa izan daitekeen arren. Errealitate honen isla pazienteen profila da: DUOko kasuen \% 68,57k ebakuntza-aurrekaria zeukan, literaturan aurkitutako emaitzekin bat eginez $(4,9,11,12,14,15)$. Gainera, ebakuntza egiteko garaian, pazienteen $\% 60 \mathrm{k}$ entzumenaren narriadura zeukan (transmisiozko hipoakusia, hipoakusia neurosentsorial edo hipoakusia misto moduan) eta \% 25,7 zuzenean kofosiarekin joan zen interbentzioa egitera. Oro har, aztertutako serieetan ebakuntza aurreko egoera audiologikoa antzekoa izan da, hipoakusia larri sakona pazienteen \% 46-\% 100ek aurkezten zuen $(4,16)$ eta kofosia pazienteen \% 39-60 artean $(11,12,17)$. PSTaegitearekin 50-60 dB-erainoko transmisiozko hipoakusia eragiten zaie pazienteei (7). Hori dela eta, oinarrizko patologia izateaz gain, egoera audiologikoak ere indikazioan eragiten du, dagoeneko transmisiozko hipoakusia moderatua duten gaixoentzat kirurgia egokiagoa izanik, PSTak eragingo lukeen entzumen-narriadura dagoeneko badutelako.

Bestalde, hipoakusia neurosentsoriala edo kofosia duten gaixoetan ere egokia izan liteke, inplante koklearra ezartzeko asmoarekin egiten bada. Izan ere, PSTarekin barrunbe itxi eta esteril bat sortzen $\mathrm{da}$, inplante koklearra kanpo-ingurunetik guztiz isolatuko duena, eta infekzio- eta estrusio-arriskua gutxitu egiten da. Besteak beste, DUOko seriean inplante koklearra eta erdiko otitis mukoso iraunkorra zuen paziente batean esplantea, PSTa eta berrinplante koklearra egitea erabaki zen barrunbe segurua ziurtatzeko.

PSTarekin ez da konplikazio intraoperatoriorik deskribatu eta, alde horretatik, ebakuntza segurutzat har daiteke. Ez da hala gertatzen kirurgia ostean; izan ere konplikazio goiztiarrak edota berantiarrak deskribatu dira pazienteen portzentaje batean. Larritasun-maila jakin bat duten konplikazioei erreparatuz, DUOko serie erretrospektiboan infekzio-portzentajea \% 25,7koa izan da, literaturan aurkitutako balioak baino altuagoa; literaturako balioak \% 5-\% 10 inguruan dabiltza eta $(11,14,15)$. Infekzioak goiztiarrak izan ziren kasuen \%44,4an, eta eragileak Pseudomonas, bakterio gram negatiboak eta S. epidermidismultirresistentea izan ziren. Bi abzesu kasu deskribatu ziren (\% 22,2): bat goiztiarra eta bestea berantiarra. Infekzioa garatu zuten gaixoetatik \%55,56k ebakuntza kirurgikoa behar izan zuen tratamendu modura antibiotikoaz gain. DUOn deskribatutako infekziotasa altuagoaren atzetik, kontuan hartu behar da infekzio guztiak kontabilizatu direla, larritasunari erreparatu gabe, eta baliteke beste ikerketetan infekzio arinak ez zenbatu izana. Hala ere, kausa zehatza zein den ez da aztertu ikerketa honetan eta interesgarria izan liteke jatorria ezagutu eta prebenitzea, tasa murriztearen alde. Aurpegi-nerbioaren paralisiari dagokionez, gure seriean \% 2,7an agertu da, eta bestelako serieetan \% 0,4-\% 5,8 tartean deskribatu denez, espero zitekeen portzentaje gisa kontsideratu dugu $(4,12,13,18)$. DUOn agertutako bi paralisi kasuetatik, bat berez hobetu zen, eta bestea errehabilitazio bidez VI gradukoa izatetik IV. graduko paralisia izatera pasa zen. Kolesteatomarenerrezidiba \% 8,6an gertatu da DUOn, ebakuntza ostean gutxienez lau urte igaro ondoren. Errezidibaren diagnostikoa irudi bidez egin zen bi kasuetan, eta hirugarrengoan klinika gailendu zen. Serie ezberdinetako errezidibaren portzentajeak oso aldakorrak direla ikusi da, \% 1,1 izatetik \% 3,8, \% 6, edo \% 19 izatera hel daitezkeelako $(4,17,19,20)$. Belarri atzeko fistula pazienteen \% 5,7an deskribatu da DUOn, kasu guztietan konplikazio berantiarra izan zen eta denek behar izan zuten ebazpen kirurgikoa arazoa konpontzeko (paziente batek bi aldiz behar izan zuen ebakuntza fistularen itxiera lortzeko). Literaturan antzeko portzentajean deskribatu da fistularen sorrera $(4,16)$. Hipofuntzio bestibularra konplikazio gisa deskribatu da DUOko pazienteen \% 8,6an eta errehabilitazioarekin kasuen \% 100 lortu zuten hobekuntza. Serieei erreparatuz, bakar batean deskribatzen da "zorabioa" konplikazio modura, bertan \% 1,9an agertzen delarik (18).

PSTa egin ondoren jarraipena funtsezkoa da batez ere kolesteatomarenerrezidiba-kasuei begira. Ebakuntzaren ezaugarriak direla eta, ezinezkoa da barrunbearen zuzeneko ikuskapena (erabat itxita dago gantzarekin); hori dela eta, funtsezkoak dira irudi bidezko probak detekzio goiztiarra egiteko, eta aukerako probak EMNa edo OTA dira (7). Irudi-proba hautatzeko garaian aukerakoa EMNa da, ehun bigunak aztertzeko, baina zenbaitetan OTA erabiltzen da: erdiko entzukineko inplante aktiboa 
dagoenean, inplante koklearra dagoenean edo EMNarentzako kontraindikazioak daudenean, besteak beste $(9,16)$. DUOnEMNa erabili da kasuen $\% 48,6$ an, EMNa eta OTA batera $\% 8,6$ an, OTA $\% 8,6 a n$, eta ez da irudi bidezko jarraipenik egin \% 34,3an. Azken talde horretan bi egoera ezberdin azpimarra daitezke: alde batetik, ebakuntzatik denbora gutxi igaro izana eta oraindik irudi-proba egiteko momentuaren zain egotea, eta, bestetik, inplante koklearra zuten zenbait pazientetan OTA erabili beharrean, kontrolerako audiometria besterik ez dela erabili. Literaturari erreparatuz, probaaukeraketa berbera mantentzen da: EMNa da aukerako teknika, $(4,17)$ baina inplante koklear edo erdiko entzukineko inplante aktiboen kasuetan OTA gailentzen da $(9,20,21)$.

DUOn batez besteko jarraipen-denbora 3,45 urte izan da, gutxieneko jarraipena sei hilabetekoa eta gehienekoa hamar urtekoa izanik (mediana: 5,25 urte). Serie ezberdinetako jarraipen-denborak aldakorrak dira, baina gutxieneko eta gehieneko jarraipen-denborak hurrenez hurren 8 eta 120 hilabete inguruan dabiltza, eta batez besteko jarraipena $28-40$ hilabete ingurukoa da $(4,16,18,22)$.

Errehabilitazio audiologikoari dagokionez, PSTaren ostean aukera ezberdinak daude pazientearen arabera. Aipatu bezala, transmisiozko hipoakusia eragiten da, hori delaeta inplante osteointegratuak edo erdiko entzukineko inplante aktiboak aukera ona izaten dira. Beste egoera batzuetan, aldez aurretik kofosia edo hipoakusia neurosentsoriala dagoenean, inplante koklearrera jotzen da. DUOnPSTa jasan zuten pazienteen \% 45,7ri ezarri zitzaion inplante bat, eta horietatik \%50ek ebakuntza berean jaso zuten. Erabili diren gailuak honakoak izan dira: \% 62,5 inplante osteointegratuak (Ponto edo Superpower), \% 31,25 inplante koklearra, \% 6,25 erdiko entzukineko inplante aktiboa. Literaturari erreparatuz, orokorrean serie bakoitzean inplante mota bakarra erabili da aztergai ziren paziente guztietan, baina serie guztien artean gehien erabili duten inplantea koklearra izan da $(12,14,15,16,18,20,22,23)$.

\subsection{Puntu ahulak}

Pazienteen jarraipenak gutxienez bost urtekoa izan beharko luke konplikazioen inguruko emaitza guztiak jaso ahal izateko, baina 2018 arteko datuak jaso direnez, azken urteetan egindako ebakuntzen jarraipena nabarmen laburragoa izan da.

Bestalde, lagina 35 pazientek osatzen dutenez, ez du tamaina handiegirik; nahiz eta gaiaren inguruko beste serie batzuen antzekoa izan alderdi horretan.

\section{Ondorioak}

DUOko 2008-2018 arteko ikerketa erretrospektiboko emaitzak literaturaren emaitzekin alderatuta, zenbait ondorio azpimarra daitezke:

- PSTaren indikazio orokorrak mantendu egiten dira.

- PSTra heltzen den pazienteak ebakuntza-aurrekariak eta entzumenaren narriadura nabarmena izaten ditu.

- Larritasun aldetik konplikazio esanguratsu ohikoak (aurpegi-nerbioaren paralisia, kolesteatomarenerrezidiba, hipofuntzio bestibularra edota belarri atzeko fistula) antzeko maiztasunarekin gertatzen dira, baina infekzioa kopuru altuagoan deskribatu da DUOn. Ikerketa sakonago bat proposatzea egokia izan daiteke horren zergatia aztertzeko.

- Jarraipena egiteko aukerako irudi-proba EMNa da, baina egoera batzuetan OTA gailentzen da (inplanteak daudenean, besteak beste).

- Jarraipen-denbora minimo eta maximo egokiek zein izan behar duten ez dago batere adostua.

- Entzumenaren errehabilitaziorako aukera ezberdinak daude pazientearen aldez aurreko entzumenaren arabera: kirurgia bakarrean ezarri behar bada, inplante koklearra da erabiliena; aldiz, bigarren denbora batean kokatzen bada, inplante osteointegratua.

Lan honek Gipuzkoako Medikuen Elkargoak antolatutako 2020. urteko Jose Begiristain Doktorearen saria jaso du. 
1. Lustig, L. R., Limb, C. J., Baden, R. \&LaSalvia, M. T. Chronic otitis media, cholesteatoma, andmastoiditis in adults. UpToDate [Internet]. [Kontsulta: 2018-03]. Eskuragarri: https://www.uptodate.com/

2. Roland, P. S., Meyers, A. D., Gianoll, G. J., McClay, J. E., Petry, P. D., Shohet, J. A., Talavera, F., \&Windle, M. L. Cholesteatoma. Medscape.com [internet]. [Kontsulta: 2018-03]. Eskuragarri: https://emedicine.medscape.com/

3. Harris ET, Linder T. Mastoidectomy\&Epitympanectomy. Open access atlas ofotolaryngology, head and neck operative surgery [Internet]. [Kontsulta: 2018-03]. Eskuragarri: http://www.entdev.uct.ac.za

4. PrasadSC, Roustan V, Piras G, Caruso A, Lauda L, Sanna M. Subtotal petrosectomy: Surgical technique, indications, outcomes, and comprehensive review of literature: Subtotal Petrosectomy. Laryngoscope. 2017;127(12):2833-42.

5. Altuna X, Navarro JJ, Goiburu M, Palicio I. Utilidad de la petrosectomía subtotal en el tratamiento de la otitis media crónica. Acta OtorrinolaringolEsp. 2016;67(5):249-53.

6. Harris T, Linder T. Subtotal petrosectomy. Open access atlas ofotolaryngology, head and neck operative surgery. [Internet]. [Kontsulta: 2018-03]. Eskuragarri: http://www.entdev.uct.ac.za

7. Fisch, U., \&Mattox, D. Microsurgery of the skull base.Thieme. 1988.

8. Coker NJ, Jenkins HA, Fisch U. Obliteration of the middleear and mastoidc left in subtotal petrosectomy: indications, technique, andresults. AnnOtolRhinolLaryngol. 1986 Jan-Feb;95(1 Pt 1):5-11.

9. Cass, S. P., Tringall, S., Talavera, F., Meyers, A. D., \& Li, J. C. Surgical Placement of BoneAnchored Hearing Systems. Medscape.com [internet]. [Kontsulta: 2018-03]. Eskuragarri: https://emedicine.medscape.com/

10. Linder T, Schlegel C, DeMin N, vanderWesthuizen S. Activemiddleearimplants in patientsundergoing subtotal petrosectomy: New applicationforthevibrantsoundbridgedeviceanditsimplicationforlateralcranium base surgery. OtolNeurotol. 2009;30(1):41-7.

11. Parikh, A. A., \&Brookes, G. B. Subtotal petrosectomywithexternalcanaloverclosure in themanagementofchronicsuppurative otitis media. J LaryngolOtol. 1994;108(3), 197-201.

12. Leung, R., \& Briggs, R. J. (2007). Indicationsforandoutcomesofmastoidobliteration in cochlearimplantation. OtolNeurotol. 2007;28(3), 330-334.

13. Verhaert, N., Mojallal, H., \&Schwab, B. Indications and outcome of subtotal petrosectomyforactivemiddleearimplants. EurArchOtorhinolaryngol. 2013;270(4), 12431248.

14. Barañano, C. F., Kopelovich, J. C., Dunn, C. C., Gantz, B. J., \&Hansen, M. R. Subtotal petrosectomyandmastoidobliteration adultandpediatriccochlearimplantrecipients. OtolNeurotol. 2013; 34(9).

15. Vashishth, A., Fulcheri, A., Prasad, S. C., Dandinarasaiah, M., Caruso, A., \&Sanna, M. Cochlearlmplantation in Chronic Otitis Media WithCholesteatomaand Open Cavities: LongtermSurgicalOutcomes. OtolNeurotol. 2018;39(1), 45-53.

16. Casserly, P., Friedland, P. L., \& Atlas, M. D. Theroleof subtotal petrosectomy in cochlearimplantation. JLaryngolOtol. 2016;130(S4), S35-S40.

17. Muzaffar, S. J., Dawes, S., Nassimizadeh, A. K., Coulson, C. J., \&Irving, R. M. Blindsacclosure: a safeand

effectivemanagementoptionforthechronicallydischargingear. Clinotolaryngol. 2017;42(2), 473-477.

18. Polo, R., Del Mar Medina, M., Arístegui, M., Lassaletta, L., Gutierrez, A., Aránguez, G., Prasad, S. C., Alonso, A., Gavilán, J., \&Sanna, M. Subtotal petrosectomyforcochlearimplantation: lessonslearnedafter 110 cases. AnnOtolRhinolLaryngol. 2016;125(6), 485-494. 


\section{Maitane Alonso Saenz del Burgo}

19. Senn, P., Haeusler, R., Panosetti, E., \&Caversaccio, M. Petrousbonecholesteatomaremovalwithhearingpreservation. OtolNeurotol. 2011;32(2), 236241.

20. Vincenti, V., Pasanisi, E., Bacciu, A., Bacciu, S., \& Zini, C. Cochlearimplantation in chronic otitis media andpreviousmiddleearsurgery: 20 yearsofexperience. ActaOtorhinolaryngolltal. 2014;34(4), 272.

21. Henseler, M. A., Polanski, J. F., Schlegel, C., \&Linder, T. Activemiddleearimplants in patientsundergoing subtotal petrosectomy: long-termfollow-up. OtolNeurotol. 2014;35(3), 437-441.

22. Szymański, M., Ataide, A., \&Linder, T. Theuseof subtotal petrosectomy in cochlearimplantcandidateswithchronic otitis media. EurArchOtorhinolaryngol. 2016;273(2), 363-370.

23. Free, R. H., Falcioni, M., Di Trapani, G., Giannuzzi, A. L., Russo, A., \&Sanna, M. Theroleof subtotal petrosectomy in cochlearimplantsurgery-a reportof 32 casesandreview on indications. OtolNeurotol. 2013;34(6), 1033-1040. 